\title{
Amerika
}

Mémoires, identités, territoires

5 | 2011:

Allers/Retours

Allers/Retours - Migrations transatlantiques, interaméricaines et territoires littéraires en devenir

\section{Inmigración francesa y cultura popular}

Fruto sin flor de Juan B. Terán

\author{
Ana María Risco
}

\section{Résumés}

Entre fines del siglo XIX y principios del XX, la llegada de inmigrantes europeos a Tucumán, en el norte de Argentina, para realizar trabajos industriales y participar de proyectos urbanos crea la sensación de estar viviendo un crecimiento acelerado de un modo similar a Buenos Aires. Las relaciones de los intelectuales con los jefes de la industria azucarera y con los políticos resultan complejas en este contexto, ya que conforman un cam po cultural de elite, a pesar de la heterogeneidad de sus posiciones.

El presente trabajo propone indagar sobre los aportes de la inmigración francesa a la composición compleja de la cultura argentina a través del análisis de Fruto sin flor (1921), de Juan B. Terán y reconstruir las complejas relaciones entre cultura de elite y cultura popular a través de la apropiación y de la experimentación con un género masiv o como el folletín por miembros de la elite tucumana.

At the turn of the XX century the arrival of European immigrants who came to work in industries and to participate in urban projects in Tucumán, in the north of Argentina, creates a sense of witnessing and being part of an upgrowth similiar to the one happening in Buenos Aires. The relationship between intellectuals, heads or owners of the sugar industry and politicians seem ed to be complicated in this context since they constituted an elite cultural circle despite their social heterogeneity.

This paper aims at, on the one hand, investigating the extent of the contributions of the French migration to the complex richness of the Argentinean culture through the analysis of Fruto sin flor (1921) by Juan B. Terán and, on the other hand, reconstructing the complexity of relations between elite and popular cultures through appropriation and experimentation with the dime novel, a mass literary genre created by the members of elite in Tucumán. 


\section{Entrées d'index}

Keywords : popular culture, French migration, intellectual circle, dime novel, Juan

B. Terán

Index géographique : Argentine, France, Tucumán, Noroeste

Palabras claves : inmigración francesa, campo intelectual, folletín, cultura popular, Juan B. Terán

\section{Texte intégral}

Los conflictos sociales desencadenados tras el masivo ingreso de población inmigrante en Argentina entre fines del siglo XIX y principios del XX se inscriben en los análisis de los políticos dentro de los rubros de la criminología y de la pobreza. Los estadistas de la época interpretan estos datos como consecuencias de la falta de integración social de los inmigrantes y del rechazo de los nativos que en muchos casos desbordan los límites de lo admisible e incurren en actos xenofóbicos violentos. Ambos fenómenos aparecen sintetizados en la rúbrica de la incivilización o falta de educación del ciudadano y del inmigrante. La necesidad de educar al pueblo se convierte rápidamente en sinónimo de integración social, como medio para plegarse al programa nacional de fortalecimiento de una identidad argentina. De modo que la escuela comienza a verse como el instrumento ideal no sólo de instrucción ciudadana, sino también de contención social e integración efectiva de la población extranjera, siguiendo las premisas de Domingo Faustino Sarmiento inspirado en el modelo de los Estados Unidos de América (1866) ${ }^{1}$.

La llegada de inmigrantes europeos de diversos países al interior de Argentina, en particular a la región noroeste, no se produjo con el mismo grado de masividad que para Buenos Aires y para el sector pampeano.

Según Mariana Feyling, es escaso el estudio sobre la inmigración francesa en Argentina. Sin embargo, el censo de 1869 revela a Tucumán y a San Luis como las provincias con mayor población de franceses, en comparación con el resto del país, e incluso con Buenos Aires (Feyling, 2004 :74-75).

La presencia en Tucumán de un importante grupo de personas provenientes de Francia, de origen rural en una etapa de migración temprana (1830-1880), resulta altamente significativa. Precisamente, las principales área de inserción económica de la provincia se vinculan con el sector agropecuario y comercial, razón que -unida al hecho de que la mayoría de los inmigrantes franceses en dicho período son trabajadores rurales con necesidades laborales, jóvenes solteros con alto índice de alfabetización y de profesionalismo- garantizó su exitosa integración y su rápido ascenso social, en relación a los migrantes de épocas posteriores a 1880. Sin embargo, siguiendo a Feyling, se debe destacar que el agropecuario y el comercio no representan los únicos sectores en los que se destacaron los franceses. (2004:85-89).

Si bien, como señala Feyling (2004 :86), el grado de instrucción de los inmigrantes franceses puede resultar un dato engañoso en cuanto a la posición social que dichos actores ocuparan en su sitio de origen, debido a que la población francesa de la época ya gozaba de un muy elevado índice de alfabetización independientemente de la clase social de pertenencia, dicho índice de alfabetización, el alto grado de instrucción y de formación profesional en relación a la situación de Argentina incide significativamente en el desarrollo 
económico y cultural de Tucumán. Precisamente de este grupo de familias francesas que se radican definitivamente en Argentina provienen las mejoras para el crecimiento y la consolidación de la industria azucarera, principal fuente de trabajo de las provincias del norte, nucleadas por Tucumán.

Por otra parte, la injerencia de esta inmigración francesa en la cultura tucumana se ve reflejada en la labor de Paul Groussac, quien llega a Argentina en 1860. Su actuación social durante su estadía en la provincia resulta significativa. Se desempeña como periodista, escritor, profesor y director de la Escuela Normal y del Colegio Nacional y ejerce cargos de alto grado de inserción y ascenso social como el de Director de Enseñanza de la Provincia y el de Inspector Nacional de Educación (Bruno, 2006:178).

Entre otros actores sociales provenientes de Francia de reveladora actuación militar, política y cultural en la provincia Silvia Mouz recuerda a Emidio Salvigny, destacado en el ejército del General Manuel Belgrano ; al ingeniero Felipe Bertrés y su participación experimental en los primeros pasos de la instrucción pública local ; a Edmundo Buessard, Felisberto Pelissot y Juan Eugenio Labougle, quienes se involucran en el funcionamiento del Colegio San Miguel junto a su director Amadeo Jacques en 1858; a la congregación de los Padres Lourdistas (1900) de origen francés, responsables de la formación de una pléy ade de dirigentes políticos destacados. En el ámbito de la industria azucarera Mouz menciona a Luis Dode y a Julio Delacroix (desarrollo técnico), a Juan Nougués, Jorge Vergnés, León y Carlos Rougés (como fundadores de ingenios) ${ }^{2}$.

La integración social de los franceses en Tucumán se pone de manifiesto en los vínculos matrimoniales y en las redes político-económicas y culturales que logran establecer por contactos previos. En efecto, la relación entre franceses e industria azucarera se testimonia a partir del momento de mayor vigor de dicha industria, a partir de los años ochenta, luego del desarrollo técnico y de la llegada del ferrocarril a la provincia. Junto a ellos, comienzan a destacarse apellidos de nuevas familias vinculadas al sector, que llegan a establecer fuerte vínculos parentales con el poder. Un sector de los inmigrantes franceses tiene participación política activa, conformando una poderosa red con la elite dirigente tucumana de fines del siglo XIX. Según María Celia Bravo,

A comienzos de la década de 187 o, en consonancia con el dinamismo económico generado por la especialización azucarera, se produjeron movimientos en el interior de la élite tucumana y nuevas familias como los " Méndez”, los "López”, los " García ”, los "Colombres" accedieron a posiciones dominantes en la Legislatura provincial. Uno de los rasgos característicos de la élite gobernante consistió en la construcción de un cam po político fuertem ente influido por redes parentales, compleja trama de parientes, amigos y clientes, que gestaron vínculos fuertem ente jerarquizados, donde la preeminencia del grupo o la familia se anteponía a las decisiones individuales. Esta lógica podía poner en peligro relaciones de solidaridad y colaboración política contraídas laboriosamente. (Bravo, $2007: 37-38$ )

$9 \quad$ Estas redes parentales, similares a las redes establecidas por los inmigrantes para la efectiva integración social, son las que resisten durante las primeras décadas del siglo XX la injerencia absoluta del Estado nacional en la relación entre trabajadores y elite industrial tucumana. Según María Silvia Fleitas,

Los industriales azucareros se resisten a aceptar el rol del Estado como regulador de las relaciones sociales cuando quiere encauzar pacíficam ente los reclam os populares mediante medidas de control social destinadas a disciplinar e integrar el movimiento obrero al sistema. Ante el conflicto social, el sector industrial asume una rígida postura patronal, negándose a aceptar una legislación laboral que significa derivar una parte 
de sus ganancias hacia mejores salarios, seguridad y condiciones de existencia más dignas para el trabajador del azúcar. (Fleitas, 1999:169)

Un sector de la elite industrial azucarera caracterizado por su sensibilidad social, sin dejar de ser conservador, tiene un punto de apoyo en la opinión pública a través del vespertino provincial El Orden (1883-1943). La popularidad del diario, manifiesta tanto en las suscripciones como en las dos, a veces tres, páginas de publicidad de las cuatro con que se publica desde sus inicios, alcanza un crecimiento que se verá reflejado en mejoras técnicas y en el aumento del número de páginas y ventas en las dos primeras décadas de principios del siglo $\mathrm{XX}$.

El diario publica desde su primera época diversas producciones literarias, coexistiendo en sus páginas firmas de gran prestigio con otras desconocidas, de autores que colaboran espontáneamente ${ }^{3}$. La organización de concursos literarios será otro sello del diario a favor de la ilustración letrada ciudadana en consonancia con su misión determinada desde el periodismo de didactismo cívico. Entre sus publicaciones literarias se otorga desde un principio un lugar especial a los folletines, siendo irregular su publicación en sus primeros años, para convertirse en un hábito cotidiano a principios del siglo XX. Se reproducen mayormente novelas de gran éxito en Europa y algunas obras nacionales de carácter histórico. Este interés por la literatura folletinesca, fuertemente criticado por la elite letrada de la época en las mismas páginas del diario, podría interpretarse como un intento por llegar con fines no sólo didácticos sino también económico-empresariales a aquel sector social en aumento constante, resultado de las políticas de alfabetización del país. En este sentido, este hecho constituye un testimonio de la conformación del mercado editorial argentino y de la formación de un público masivo ávido de dos prácticas : la lectura y la escritura ; en definitiva, de la participación popular en el ejercicio de estas prácticas como una suerte de democratización de la cultura letrada.

El cultivo en Argentina de las novelas breves o novelitas de diez centavos, como se sabe, alcanza su auge de producción entre las décadas del diez y del veinte, ligado al éxito precedente del folletín decimonónico. Los casos de las Ediciones Mínimas (1915) y de La Novela Semanal (1917), por mencionar sólo dos de las más populares, es elocuente en este sentido ${ }^{4}$.

Desde Tucumán, un sector de la elite intelectual tucumana decide participar de esta apertura de la cultura letrada realizando experimentos con las expresiones de la cultura popular. Dicho sector adopta el género del folletín como espacio preferencial de experimentación, y lleva a cabo el proyecto de publicación de una serie de novelas breves en la colección de La Novela del Norte, editada por Miguel Agüero y Benito Viola durante el transcurso de 1921 y 1922 (Zelaya de Nader, $1995: 1$ ). En su primer número del 15 de marzo de 1921 se publica Fruto sin flor de Juan B. Terán (1880-1938), representante local de la llamada Generación del Centenario, nucleada en Tucumán bajo el proyecto de la Revista de Letras y Ciencias Sociales (1904-1907), y creador-fundador de la Universidad de Tucumán ${ }^{5}$. Según Enrique Kreibohm, Terán, siempre dispuesto a fomentar y promover las iniciativas que impliquen dinamismo cultural, respalda con esta obra con su ya prestigioso nombre el proyecto de la Novela del Norte (Kreibohm, 1964 : 20 y Martínez Zuccardi, 2005 : nota 173 p. 89).

Considerada como un testimonio que documenta el Tucumán de principios del siglo XX, las apreciaciones de la crítica sobre la novela-folletín de Terán incurren en una clara contradicción. Por un lado, valoran negativamente la novela por 
considerar que carece de suficientes referencias a la vida social tucumana y por la ausencia de la interacción entre los personajes, destacando el predominio de la mirada externa autoritaria del narrador omnisciente. Por otro lado, sostienen que la novela de Terán documenta los inicios de la industria azucarera y de sus relaciones con la inmigración francesa ${ }^{6}$.

Un antecedente o primer boceto de esta novela-folletín se publica a principios del siglo XX en el número 29 (1906) de la Revista de Letras y Ciencias Sociales como "Cartas de Adolfo Revecín » bajo el seudónimo de Baltazar Montalvo. Esta carta contiene una sugerente nota del autor en la cual se declara que se trata de «apuntes para una novela sobre la psicología de la inmigración». Esta declaración ha sido interpretada por Kreibohm en un primer índice temático de la obra de Terán (primer intento de sistematizar su obra completa dispersa) como «Capítulos de una novela de sociología de la inmigración ». Obsérvese que Kreibohm interpreta como sociología la caracterización de la carta de los apuntes de una novela de "psicología de la inmigración » (Cfr. 1964:44).

En el momento de publicación de la novela de Terán (1921) la industria azucarera ya se había desarrollado en Tucumán y se venía perfeccionando tras las continuas crisis industriales de fines del siglo XIX. En efecto, en 1907 (año posterior a la publicación de la Carta de Montalvo) se especializa técnicamente el sector azucarero gracias a la creación de la Estación Experimental Agrícola, producto de los esfuerzos legislativos de un destacado personaje del ámbito cultural de la provincia, el señor Alfredo Guzmán (Páez de la Torre, 1987 : 603).

El relato narrativo se remonta mediante saltos temporales a las tres últimas décadas del siglo XIX, época en que, en efecto, el interés por la industria del azúcar se torna una cuestión provincial y nacional, especialmente después de 1875. La llegada del ferrocarril a Tucumán en octubre de 1876 constituye uno de los impulsos decisivos para su desarrollo, expansión y modernización (Paéz de la Torre, $1987: 550$ y 555 y Vidal, 2009 :15). En el texto de Terán, las referencias a los inicios de dicha industria, sus relaciones con la política y la inmigración francesa se relatan a partir de la caracterización de los padres de las familias protagonistas de la trama, Don José Ramírez y Pablo Révecin. Se destaca, sobre todo la focalización discursiva en este último personaje, de quien se relata extensamente su origen francés y su llegada a América.

La novela de Terán, si bien se publica en 1921 como texto completo, está fechada, aunque de forma imprecisa, al finalizar el relato, a modo de juego con el lector. La imprecisión temporal se manifiesta en la transcripción incompleta del año señalado por medio de puntos suspensivos : "191..." (Terán, 1921 : 42). Si tenemos en cuenta que el juego de saltos temporales en la novela se remonta a momentos previos a la década de 1870 , podríamos afirmar que el tiempo narrativo completo abarca temporalmente desde los inicios de la política inmigratoria durante la década de 1860 hasta la primera década del siglo XX. Esto último queda demostrado por medio de las referencias explícitas en el texto a las innovaciones que los franceses traen a la industria y a su desarrollo gracias a los alcances de la investigación en esta área, innovaciones atribuidas en la trama al personaje de Gastón Révecin. De modo que la novela podría considerarse un testimonio no sólo de la relación entre la industria azucarera y la inmigración francesa, como lo demuestra María Trinidad Esma (1964), sino también de los proyectos basados en los avances científicos que se estaban poniendo en marcha a principios del siglo XX, a través de la Estación Experimental Agrícola y del perfeccionamiento de argentinos en escuelas 
politécnicas en el extranjero.

El folletín Fruto sin flor ha sido caracterizado, por un lado, como testimonio de una etapa emergente de la producción novelística del noroeste argentino, y por el otro, como boceto de una obra inconclusa. Esta apreciación estaría avalada por dos circunstancias : por un lado, por el título de la colección en que se publica, hecho que determina su lectura como parte del género narrativo novela cultivado por una región concreta del país, en cuyo primer número, además, se especifican los propósitos de un proyecto editorial de amplio alcance; y, por otro lado, por la carta del mismo autor, publicada en la Revista de Letras y Ciencias Sociales, que anticipa su enunciación.

El juicio académico posterior considera la novela de Terán como desequilibrada en valor literario ; de allí su caracterización como boceto de novela, hecho atribuido a la preferencia del autor por la escritura ensayística. Esta valoración presupone, por una parte, una lectura del texto de Terán que busca profundidad psicológica y complejidad argumental ; y, por otra parte, una postura localista o regional que intenta establecer los inicios de un género en formación, lo que conduce a considerarla como una de las primeras expresiones de escritores tucumanos que experimentan con este género. La crítica admite, de este modo, el hecho ya establecido y corroborado de que la producción literaria de valor del noroeste argentino entre fines del siglo XIX y principios del siglo XX es fundamentalmente lírica.

Nilda Flawiá de Fernández (1990) circunscribe el folletín de Terán al fenómeno de las novelas populares de principios del siglo $\mathrm{XX}, \mathrm{y}$ reconoce en ella la intencionalidad de instaurar en la narrativa argentina la problemática provincial con referencias locales específicas ; una labor que, a nuestro entender, ya había comenzado a gestarse años anteriores en las letras tucumanas desde el teatro, por ejemplo, en obras como Cañas y Trapiches del uruguayo radicado en Tucumán, Alberto García Hamilton (1909)7.

Entre los alcances editoriales de La Novela del Norte, explicitados en un texto titulado Nuestra Palabra, se hace referencia al apoyo del proyecto sostenido por los « intelectuales tucumanos » de prestigio. Se destaca la entrega del primer número con la firma consagrada de Terán ${ }^{8}$. Además, se sintetizan tres propósitos de su programa editorial :

10 Propiciar con estas nov elas cortas al alcance de todos, la producción literaria de los escritores tucumanos, y a sean éstos consagrados o nov eles.

$2^{\circ}$ Dar cada tres meses al publicar nuestro ILUSTRADO SUPLEMENTO de 40 páginas formato may or que la nov ela, participación utilitaria a sociedades y com unidades benéficas por medio de inserción de avisos obtenidos por las mismas en dicho número.

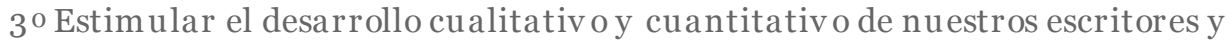
aficionados con un premio anual de 250 \$ como mínimo, a una obra que versando sobre tema libre, obtenga, previo concurso literario, el concepto de m ejor entre las presentadas, la que se publicará en un número denominado EXTRAORDINARIO de 80 páginas. 9

Como puede observarse resulta explícita la intención de difundir la literatura de escritores tucumanos entre un público extenso ${ }^{10}$.

Según la representación que tienen los editores acerca del funcionamiento del incipiente campo literario tucumano, la publicación en el primer número de $L a$ Novela del Norte del texto de Terán, intelectual ya consagrado en el medio, funcionaría como garantía de una obra con ribetes ilustrados indiscutibles. En este gesto puede percibirse además la representación del público lector. Si bien se trata de una publicación al alcance de todos, el prestigio que precede a Juan 
B. Terán con la fundación de la universidad es aprovechado para incluir en ese indeterminado todos tanto a los letrados como al ciudadano en formación. Evidentemente ese todos no puede interpretarse, en este contexto, como masivo, ya que se refiere a un sector social fundamentalmente ilustrado.

Esto se verifica si tenemos en cuenta que la novela de Terán no versa sobre los tradicionalmente conocidos temas del folletín y de la novela popular. El autor construye una narración abocada fundamentalmente a la problemática política durante unas ficticias elecciones de renovación legislativa en la provincia. Los protagonistas de la novela pertenecen a las dos familias ya mencionadas, que representan dos líneas de la aristocracia tucumana -Ramírez y Révecin-, una de cepa criolla (el patriciado tucumano) y la otra de origen inmigrante (en este caso, francés, clase enriquecida con la industria y el comercio). Ambas fuertemente comprometidas y ligadas a la política y a la industria azucarera.

Los elementos propios de las novelas populares, asociados por lo general a tópicos comunes como amores, desencuentros, engaños, crímenes y elementos formales -la dosificación del suspenso y el final sorpresivo, entre otros ${ }^{11}$-, sólo aparecen en la narración como un elemento agregado, no estructural. En efecto, el final resulta sorpresivo, ya que, habiéndose concentrado el relato en mostrar la corrupción del proceso electoral tucumano, concluye con una sentencia en la que se menciona el casamiento de uno de los protagonistas, Gastón Révecin, con una de las hijas de la familia Ramírez, Emilia, sin que su romance, apenas insinuado en la trama, constituya en ningún momento el eje estructural de la novela. De este modo, se testimonia la práctica matrimonial entre criollos e inmigrantes propuesta como solución integradora, como signo de una integración socio-cultural percibida como efectiva, y al mismo tiempo, como índice de la costumbre exogámica de la colectividad francesa en Tucumán (Curia de Villecco y Bolognini, 1992 : 17-18).

El alto contenido didáctico en relación a la ética ciudadana en el comportamiento durante un proceso electoral se evidencia enunciativamente en el detenimiento discursivo en los detalles de dicho proceso, en los debates políticos entre los ciudadanos de la elite social tucumana y en las reflexiones políticas del narrador en la presentación de los personajes.

No obstante lo señalado con respecto a los elementos que se identifican con el género folletín, se registra un rasgo característico de las novelas populares : los personajes son estereotipos sin profundidad psicológica ni complejidad de vida. Este aspecto constituye uno de los fundamentos de la valoración negativa de la novela de Terán como boceto por parte de la crítica académica, sin tener en cuenta el género popular en el que se inscribe, o, al menos, en el que finalmente el autor decide inscribirse, tal como veremos.

María Delia Paladini menciona una carta atribuida a Terán publicada en el No 29 de la Revista de Letras y Ciencias Sociales en 1906, firmada por el seudónimo de Baltasar Montalvo, titulada « Cartas de Adolfo Révecin ». Mientras en otros estudios se considera esta carta como el espacio para-textual desde el cual se completan los sentidos ausentes de la novela (Flawiá, 1990 : 30), Paladini compara los tonos de la reflexión del personaje común (Adolfo Révecin), llegando a proponer una identidad entre el personaje de Adolfo y el autor Terán.

30 La circunstancia de la publicación de la carta con una anticipación de aproximadamente quince años a Fruto sin flor es significativa a la hora de considerar la obra en su gestación enunciativa como novela. En este sentido, resulta llamativa la presencia al final de la carta de una nota firmada con la inicial 
$T$, inicial atribuida a Terán.

La carta y la nota, ambas apócrifas, tienen una funcionalidad evidentemente ficticia. Ponen de manifiesto la complejidad lúdica de la autoría del relato : la carta está firmada por Baltasar Montalvo, cuya firma, según la nota, es un seudónimo literario adoptado de un antepasado que enmascara a un amigo excéntrico de $T$. El autor de la nota ( $T$ ), a su vez, reconoce que la carta que se publica en la prestigiosa revista es parte de una colección de este misterioso Montalvo, presentada como borrador de una misiva «que debió dirigir a un amigo»-Antonio, el destinatario-, y de la que $T$ duda que se haya enviado y leído efectivamente, pues destaca que « todo era inconcluso en él ». La identidad de Montalvo se revela a través de esta nota : la colección de cartas que transcribe la revista pertenece a Adolfo Révecin, tal como lo declara el título del texto.

Además de revelar la identidad del que firma la carta -que no debemos identificar necesariamente con Juan B. Terán sin tener en cuenta el aspecto ficticio de Montalvo y el prototipo narrativo-novelístico de fondo-, la nota menciona el hecho de que este amigo misterioso ha entregado a $T$ un manuscrito para su revisión y posible publicación : Apuntes para una novela sobre psicología de la inmigración. Tal como se presenta, el autor de la novela sería el propio Montalvo/Révecin. T presenta el hecho de la delegación del manuscrito no como un pedido de redacción de una novela, sino como de supervisión editorial de la misma. A continuación brinda algunos detalles argumentales de dicha obra y menciona a Gastón y a Adolfo Révecin como sus protagonistas, hijos de la unión que valora como irregular, entre un inmigrante francés que, sostiene, ascendió a pionner y millonario, y una mujer criolla, ausente en la narración. Estos personajes constituyen dos tipos que sintetizan el carácter del argentino : uno es el extranjero, representado en Gastón, heredero de su padre francés en cuanto a sus características morales-espirituales, dibujado como « emprendedor y atrevido », con « salud enérgica »y " genio alerta»; el otro es la síntesis entre el europeo y el indígena, representado por Adolfo, quien asume « la herencia semi-indígena de la madre» y se caracteriza por ser «triste, apático, débil y soñador » (Nota de $T, 1907$ : 288). Este segundo personaje llama la atención de $T$, de quien se transcriben las cartas cuya continuidad en la revista se promete. Además, este personaje representa simbólicamente la postura de Terán sobre el ser americano y su aporte polémico a las reflexiones de la Generación del Centenario.

La crítica académica identifica ambos personajes, el de la carta y el de la novela, como pertenecientes a un proyecto de novela mayor. Considera esta delegación del manuscrito de Montalvo a $T$, que en la carta tiene una función ficcional, como base para considerar Fruto sin flor como el bosquejo de un proyecto inconcluso, ya que esta novela finalmente publicada en 1921 no constituiría la concreción del proyecto inicial por sus deficiencias literarias.

Sin embargo, resulta válido considerar que la publicación del proyecto de novela mencionado en la nota de $T$ en la Carta de Montalvo/Adolfo Révecin se concreta en cierta medida en 1921 y representa la cristalización del proyecto de Terán, quien decide su edición en el formato de novela popular. El alto contenido de crítica y denuncia política se circunscribe, evidentemente, a la pedagogía del ciudadano de la que Terán era un ferviente propulsor. Por lo tanto, consideramos factible leer Fruto sin flor no como el esbozo de un proyecto inconcluso sino como la concreción de un proyecto pensado para articular cultura letrada y cultura popular con fines didácticos. 
El juicio descalificador del valor literario de esta novela por parte de la crítica, presupone un juicio en contra de la novela popular, ya que se manifiesta en su consideración como boceto de un proyecto inconcluso. Esta valoración se fundamenta en dos circunstancias : en primer lugar, el medio de su publicación, que determina su lectura como novela ; en segundo lugar, la carta de Adolfo, que condiciona, a través del anuncio en la nota final de un proyecto de novela mayor, su interpretación como proyecto inconcluso. Ambas dejan de lado la consideración de dicha obra como articulación experimental entre cultura letrada y cultura popular, evidente en la conexión entre la carta publicada por la Revista de Letras y Ciencias Sociales en 1906 y la novela corta de 1921, representando dicha carta un anuncio de lo que más tarde se concretaría como narrativa popular.

Evidentemente la función didáctica de esta obra está íntimamente relacionada con la misión educadora de Terán y su mensaje a la juventud universitaria con intenciones de llegar a un público mayor. La cuestión de la inmigración resulta en este contexto un pretexto con múltiples finalidades : incorporar su problemática en Tucumán ; abordar el tema de los aportes de la colectividad francesa a la cultura argentina ; destacar la formación positivista, apuntando siempre a la ciencia sin descuidar los valores espirituales, educación cientificista necesaria en el desarrollo económico de la provincia (proyecto de Terán) y, por último, dramatizar, sin profundidad psicológica, la relación entre los personajes de diversa procedencia y agregar en ocasiones inconexas elementos amorosos de aparente gusto popular, experimentando con un género que pronto abandona.

\section{Bibliographie}

Bravo, María Celia, “ Elite tucumana, cuestión regional y proy ecto universitario para el norte argentino (1907-1929) ", en Boletín Americanista, Año LVII, No 57 , Barcelona : 2007 ; pp. 35-52.

Bruno, Paula, "Paul Groussac. Un articulador cultural en el pasaje del siglo XIX al XX argentino", en Araucaria, primer semestre, año/vol. 8, número 015, Universidad de Sevilla, Sevilla : 2006 ; pp. 176-186.

Curia de Villecco, María Elena y Bolognini, Víctor Hugo, La inmigración en Tucumán, Tucumán : IHPA, Facultad de Filosofía y Letras, Universidad Nacional de Tucumán, 1992.

Esma, María Trinidad, La inmigración francesa a través de una novela de Juan B. Terán, Tucumán : Centro del Pensamiento Argentino, Facultad de Filosofía y Letras, Universidad Nacional de Tucumán, 1982.

Feyling, Mariana, "La inmigración francesa temprana en Tucumán : 1830-18801", Travesía, $\mathrm{N}^{0} 7 / 8$, primer y segundo sem estre de $2004 ;$ pp. 73-101.

Flawiá de Fernández, Nilda María y Steimberg de Kaplán, Olga Ruth, Tucumán Siglo $X X$ : Perfiles estéticos y narrativos, Tucumán : Ediciones El Graduado, 1985.

Flawiá de Fernández, Nilda María, “ El discurso literario de Juan B. Terán ”, en Nilda Ma. Flawiá de Fernández (dir.) y Ma. Eugenia Orce de Roig (ed.), Argentina en su literatura, Tucumán : INSIL, vol. 5, 1990 ; pp. 17-42.

Fleitas, María Silvia, “ El pensamiento político y social de la élite azucarera del noroeste argentino, 1910-1930 ”, en Revista de Indias, 1996, vol. LVI, núm. 206 ; pp. 167-195.

Kreibohm, Enrique, Juan B. Terán. Vida y obra, Tucumán : Universidad Nacional de Tucumán, 1964. 
Lagmanovich, David, La literatura del noroeste argentino, Rosario : La Biblioteca, 1974.

Martínez Zuccardi, Soledad, Entre la Provincia y el Continente. Modernismo y modernización en la Revista de Letras y Ciencias Sociales (Tucumán, 1904-1907), Tucumán : IIELA, Facultad de Filosofía y Letras, Universidad Nacional de Tucumán, 2005 .

Martínez Zuccardi, Soledad, “ El Norte y la nación en Juan B. Terán, Ricardo Rojas y Alfredo Coviello ", en Telar, Año IV, $\mathrm{N}^{0}$ 5, IIELA, Facultad de Filosofía y Letras, Univ ersidad Nacional de Tucumán, 2007 ; pp. 137-160.

Montalvo, Baltasar : “ Cartas de Adolfo Révecin ”, en Revista de Letras y Ciencias Sociales, Tucumán, Tomo V, No 29, 1906.

Mouz, Silvia, “ Colonias francesas en la provincia de Tucumán ”, en La Gaceta de Tucumán, sábado 15 de Julio de 1989, reproducido en el sitio web : http://genfrancesa.com/inmigracion_francesa/Colonias/nota_fceses_tucuman.htm (fecha de consulta :13/10/2011).

Páez de la Torre, Carlos (h.), Historia de Tucumán, Buenos Aires : Plus Ultra, 1987.

Páez de la Tor re, Carlos (h.), Pedes in terra ad sidera visus. Vida y tarea de Juan B. Terán (1880-1938), Tucumán : Centro Cultural Alberto Rougés, Fundación Miguel Lillo, en coedición con Academia Nacional de la Historia y Academia Argentina de Letras, 2010.

Paladini, María Delia, Una novela de Juan B. Terán, Buenos Aires : Universidad de Buenos Aires, Facultad de Filosofía y Letras, Instituto de Literatura Argentina “Ricardo Rojas”, 1971.

Pierini, Margarita (Coord.), La novela semanal (Buenos Aires, 1917-1927). Un proyecto editorial para la ciudad moderna, Madrid : Consejo Superior de Investigaciones Científicas, Colección Literatura Breve, 2004.

Risco, Ana María, Comunicar literatura, comunicar cultura. Variaciones en la conformación de la Página Literaria del diario La Gaceta de Tucumán entre 1956 y 1962, Tucumán : Colección Tesis, Departamento de Publicaciones, Facultad de Filosofía y Letras, Universidad Nacional de Tucumán, 2009.

Risco, Ana María, “ Tensión entre cultura letrada y cultura popular en Cañas y Trapiches ", ponencia inédita presentada en el XVIII Congreso Internacional de Teatro Iberoamericano y Argentino, GETEA, Facultad de Filosofía y Letras, Universidad de Buenos Aires, 2009.

Risco Fernández, Gaspar, Cultura y Región, Tucumán : Centro de Estudios Regionales e Instituto Internacional " Jacques Maritain ”, Universidad Nacional de Tucumán, 1991.

Rivera, Jorge B., El Folletín y la novela popular, Buenos Aires : Centro Editor de América Latina, 1968.

Sarmiento, Domingo F., Las Escuelas (Informe), New York : sin editorial, 1866.

Terán, Juan B., Fruto sin Flor, Tucumán : La Novela del Norte, 15 de marzo de 1921.

Vidal, Lucía, “ Policía, azúcar y control social, 1876-1881" en Luis Marcos Bonano y Roberto Pucci (comps.), Autoritarismo y dictadura en Tucumán. Estudios sobre cultura, política y educación, Buenos Aires : Catálogos, 2009 ; pp. 15-35.

Zelay a de Nader, Honoria, "Las novelitas de 10 centavos ", en El Periódico, sección "Vivir Mejor ", San Miguel de Tucumán, Nº 30, Año I, domingo 28 de mayo de 1995 ; p. 1.

\section{Notes}

1 cf. Domingo F. Sarmiento : Las Escuelas (Informe), New York, sin editorial, 1866.

2 «La industria azucarera también debe mucho a Francia en sus orígenes. Franceses fueron los que instalaron las primeras máquinas a vapor en el ingenio Baltazar Aguirre, en Floresta ; Luis Dode y Julio Delacroix, constructor también este último del primer molino hidráulico local y una fantástica obra de ingeniería para 1871, el puente sobre el Río Salí. Después llegarían los fundadores de ingenios : Juan Nougués (San Pablo, 1832), y de allí en adelante Evaristo Etchecopar (Lastenia), Clodomiro 
Hileret (Lules y Santa Ana), Jorge Vergnés (Santa Bárbara), León y Carlos Rougés (Santa Rosa). Las grandes fincas y las curtiembres están llenas de apellidos franceses : los Apestey, los Barquet, los Mothe y tantos más, en diversas zonas de la provincia. / Nuestra iglesia Catedral fue diseñada por un francés -también exiliado revolucionarioel ingeniero Pedro Dalgare Etcheverry, y la decoró un compatriota, Félix Revol. Fueron franceses el primer historiador de la economía local. Alfredo Bousquet (autor del " Sistema rentístico de la provincia de Tucumán ", 1878) ; el gran teólogo, formador de la conciencia de varios gobernantes, Fray Angel María Boisdron, domínico, y dos de los grandes médicos de Tucumán en el siglo pasado, los doctores Víctor Bruland -ex cirujando del sitio de Montevideo- y Carlos Nanterne. "Ver "Colonias francesas en la provincia de Tucumán », artículo publicado en el diario La Gaceta de Tucumán, el Sábado 15 de Julio de 1989.

3 Para un análisis detallado de las relaciones entre periodismo y literatura en vinculación con otros diarios tucumanos y del concepto de "cultura/literatura " suby acente ver Ana María Risco (2009).

4 Ver Margarita Pierini (2004). Por su parte, Nilda Flawiá de Fernández (1990) y Honoria Zelaya de Nader (1995) relacionan el éxito de las ediciones populares con el resultado de la alfabetización y con cuestiones relacionadas con las políticas de inmigración y señalan el aporte efímero de Tucumán a la fiebre folletinesca de la época.

5 Carlos Páez de la Torre (hijo) caracteriza a este grupo de intelectuales como los “ responsables de la 'toma de conciencia cultural' de la provincia" (1987 :604-605 y 2010 : 67). Por su parte, Soledad Martínez Zuccardi (2005) ha profundizado estas cuestiones en un estudio sobre la formación cultural que gira en torno a la Revista de Letras y Ciencias Sociales, dirigida por Ricardo Jaimes Frey re y redactada por Juan B. Terán y Julio López Mañán.

6 Los trabajos que abordan el análisis de dicha novela corresponden a María Delia Paladini (1971), Nilda Flawiá de Fernández (1990) y Olga R. Steimberg de Kaplán y N. Flawiá de Fernández (1985). En este último caso, las autoras hacen referencia, además, al trabajo de María Trinidad Esma sobre la inmigración francesa en la obra de Terán.

7 En Cañas y Trapiches García Hamilton, a diferencia de Terán, sí incluye un elemento popular como ser las creencias mitos y leyendas de Tucumán relacionados con el mundo de la industria azucarera (Risco, 2009).

8 «[...] engalanamos orgullosamente nuestras páginas con la pluma repleta de belleza y de estilo del distinguido intelectual doctor Juan B. Terán, escritor y maestro » (La Dirección, La Novela del Norte, 1921, $\mathrm{N}^{\mathrm{0}} 1$ )

9 La dirección, “ Nuestra Palabra ”, La Novela del Norte, Tucumán, № 1, 15 de marzo de 1921 , p. 2. Lo resaltado en may ú sculas pertenece al original.

10 Lam entablem ente no contamos con información suficiente para establecer si estos propósitos fueron realmente cumplidos. La Universidad Nacional de Tucumán ha conservado sólo la novelita de Terán, y a que forma parte de la producción del primer rector de dicha institución.

11 Sobre las características de la nov ela popular cfr. Jorge Rivera (1968).

\section{Pour citer cet article}

Référence électronique

Ana María Risco, « Inmigración francesa y cultura popular », Amerika [En ligne], 5 | 2011, mis en ligne le 20 décembre 2011, Consulté le 14 mars 2012. URL :

http://amerika.revues.org/2597 ; DOI : 10.4000/amerika.2597

\section{Auteur}

Ana María Risco

Consejo Nacional de Investigaciones Científicas y Técnicas (CONICET)

Universidad Nacional de Tucumán 
anamrisco@gmail.com / anamrisco@yahoo.com.ar

\section{Droits d'auteur}

(c) Tous droits réservés 